\title{
Implantable loop recorder for monitoring patients with congenital heart disease
}

\author{
Michael Huntgeburth ${ }^{1,2 \#}$, Christopher Hohmann ${ }^{1 \#}$, Peter Ewert ${ }^{2}$, Sebastian Freilinger $^{2}$, \\ Nicole Nagdyman ${ }^{2}$, Rhoia Neidenbach ${ }^{2}$, Lars Pieper $^{3}$, Felix Pieringer ${ }^{2}$, Carsten Lennerz ${ }^{4}$, \\ Harald Kaemmerer ${ }^{2 *}$, Christof Kolb ${ }^{4 *}$
}

${ }^{1}$ Center for Adults with Congenital Heart Disease, Clinic III for Internal Medicine, Department of Cardiology, Heart Center, Medical Faculty, University Hospital of Cologne, Cologne, Germany; ${ }^{2}$ Department of Congenital Heart Disease and Pediatric Cardiology, German Heart Center Munich, Technical University of Munich, Munich, Germany; ${ }^{3}$ Chair of Behavioural Epidemiology, Institute of Clinical Psychology and Psychotherapy, Technical University of Dresden, Dresden, Germany; ${ }^{4}$ Department of Electrophysiology, German Heart Center Munich, Technical University of Munich, Munich, Germany

Contributions: (I) Conception and design: M Huntgeburth, C Hohmann, H Kaemmerer, C Kolb; (II) Administrative support: M Huntgeburth, C Hohmann; (III) Provision of study materials or patients: M Huntgeburth, C Hohmann, P Ewert, N Nagdyman, F Pieringer, H Kaemmerer, C Kolb; (IV) Collection and assembly of data: M Huntgeburth, C Hohmann, S Freilinger, H Kaemmerer, C Kolb; (V) Data analysis and interpretation: All authors; (VI) Manuscript writing: All authors; (VII) Final approval of manuscript: All authors.

"These authors contributed equally to this work.

*These authors contributed equally to this work.

Correspondence to: Michael Huntgeburth, MD. Center for Adults with Congenital Heart Disease (ACHD), Clinic III for Internal Medicine, Department of Cardiology, Medical Faculty, Heart Center, University Hospital of Cologne, Kerpener Str. 62, 50937 Cologne, Germany. Email: michael.huntgeburth@uk-koeln.de.

Background: Patients with congenital heart defects (CHD) are prone to residua, sequels and complications from the underlying anomaly, where cardiac arrhythmias are one of the major causes for hospitalization, morbidity and mortality. The importance of the subcutaneous implantable loop recorder (ILR) for the detection and documentation of significant arrhythmias has increased over the last years. To date, however, there is little data on ILR use in the CHD population.

Methods: In this single center, retrospective observational study, all CHD-patients with an ILR were identified who were under care of the German Heart Center Munich between February 2015 and January 2019. The primary endpoint of the study was the detection or exclusion of significant arrhythmias during follow-up in CHD-patients who had received an ILR. The secondary endpoint was to determine whether ILR findings influenced patient management, defined as initiation or adjustment of medication, cardioversion, electrophysiologic study, catheter ablation, or implantation of cardiac implantable electronic devices (CIEDs) such as pacemakers (PM) or implantable cardioverter-defibrillators.

Results: An ILR was implanted in 33 CHD-patients (mean age, $43 \pm 20$ years; $42.4 \%$ female) with CHD. During a mean observation period of $697 \pm 433$ days, clinically relevant arrhythmias, correlating with the patients' complaints and symptoms, were detected in 19 patients $(59.4 \%)$, encompassing supraventricular tachycardia $(n=10)$, supraventricular or ventricular ectopic beats $(n=10)$, non-sustained ventricular tachycardia $(n=2)$, ventricular tachycardia $(n=2)$, and bradycardia $(n=2)$. In 9 patients $(28.1 \%)$ the detected arrhythmia was considered an event requiring treatment. Treatment modalities included catheter ablation $(n=5)$, modification of antiarrhythmic drug regime $(n=2)$, adaptation of anticoagulation therapy $(n=2)$, or implantation of a subcutaneous ICD $(n=1)$. Regarding the occurrence of cardiac arrhythmias or a related need for therapeutic intervention, no significant differences were identified with respect to WHO functional class, the presence of pulmonary arterial hypertension or reduced resting peripheral oxygen saturation.

\footnotetext{
$\wedge$ ORCID: 0000-0003-2533-4587.
} 
Conclusions: In symptomatic CHD-patients at risk for life-threatening cardiac events, ILR has a considerable complementary diagnostic value for the detection and differentiation of benign and malignant arrhythmias. Considering the overall low risk of complications, ILR implantation should be considered in patients with CHD of any complexity who need medium or long-term arrhythmia monitoring, especially if short-term Holter monitoring cannot provide sufficient diagnostic certainty.

Keywords: Adult congenital heart disease (ACHD); sudden cardiac death; implantable loop recorder; cryptogenic stroke; embolic strokes of undetermined source (ESUS); arrhythmias; patient management

Submitted Jul 30, 2020. Accepted for publication Nov 16, 2020.

doi: $10.21037 / \mathrm{cdt}-20-677$

View this article at: http://dx.doi.org/10.21037/cdt-20-677

\section{Introduction}

Up to 1.35 million patients worldwide are born with a congenital heart defect (CHD) each year, the most common isolated congenital organ abnormality (1). Approximately $30 \%$ of CHD are severe anomalies, while the remaining $70 \%$ include moderate or minor heart defects. In recent decades, the survival probability of these patients has improved significantly, particularly due to the major advances in cardiac surgery and interventional cardiology and the development of new pharmaceutical therapies. The primary high mortality of CHD, which was above $80 \%$ only a few decades ago, has been reduced to such an extent that more than $90 \%$ of those affected currently reach adulthood (2).

Despite the decrease in mortality, morbidity remains high and cardiac arrhythmias are a leading cause of the high hospitalization rate and cardiac death in the long-term course (3-5). The clinically most relevant tachyarrhythmias include supraventricular tachycardia, mostly atrial tachycardia or flutter, as well as mono- and polymorphic ventricular tachycardia and ventricular flutter or fibrillation $(6,7)$. Bradycardia due to sinus node dysfunction or AVblock are also clinically relevant complications in the long-term course in CHD. Especially in complex cases (e.g., after atrial redirection, after Fontan operation, in cyanotic CHD, in pulmonary hypertension, particularly in Eisenmenger syndrome) any significant arrhythmia is often poorly tolerated and may result in syncope, cardiac decompensation or even death (8). Accordingly, there is a clinical need for the correct and timely identification of patients with CHD at risk for complications using longterm, real-time, monitoring of arrhythmia as short-term monitoring may miss infrequent arrhythmic or events of short duration.
While in patients with acquired heart disease, the subcutaneous implantable loop recorder (ILR) has become increasingly used in recent years to detect and document clinically relevant and threatening arrhythmias, there is little data on its use in the CHD population $(9,10)$. In the current study we aimed to determine the mid-term course and outcome of patients with CHD who had been receiving an ILR for the identification of clinically relevant arrhythmias. We present the following article in accordance with the STROBE reporting checklist (available at http:// dx.doi.org/10.21037/cdt-20-677).

\section{Methods}

\section{Study population}

This single center, retrospective observational study was performed at the Department of Congenital Heart Disease and Pediatric Cardiology of the German Heart Centre Munich. All patients with CHD after an ILR implantation who underwent follow-up care, were consecutively included from February 2015 to January 2019 in the order that they presented at our institution and were not selected in prior.

Inclusion criteria for the present study were a confirmed diagnosis of CHD, exclusion criteria were lack of cognitive competence to consent to research, and refusal to consent.

Medical records were reviewed for patient demographics, cardiac and non-cardiac diagnosis, surgical, interventional or electrophysiological procedures, clinical condition and medication.

The indication for an ILR implantation was the presence of symptoms of unknown origin, particularly palpitations or syncope, and/or a history of symptomatic 
tachycardia or bradycardia after cardiac surgery as well as cryptogenic stroke or embolic strokes of undetermined source (ESUS). The decision to implant an ILR had been made by a Heart Team consisting of at least an experienced electrophysiologist and a pediatric or congenital cardiologist.

The study was conducted according to the principles expressed in the Declaration of Helsinki (as revised in 2013). All clinical evaluations were part of the regular management of the patients who required these for management of their medical conditions. No additional examination was performed for the sole purpose of the study. All data were assessed and analyzed in an anonymous way. The study was reviewed and approved by the local Ethics Committee of the medical faculty at the University of Cologne (vote 201526) and individual consent for this retrospective analysis was waived.

\section{Implantation of Loop-recorders}

All ILR had been implanted subcutaneously as recommended by the manufacturer using the incision and insertion tool. Device programming was at the discretion of the implanting electrophysiologist in collaboration with the patient's cardiologist. All devices were connected to the network system of the respective manufacturer for remote monitoring. Patients had been discharged on the day after implantation and were seen regularly at the outpatient clinic for routine patient care. All recordings of the ILR were regularly reevaluated by an experienced electrophysiologist.

\section{Outcome measures}

The primary endpoint of the present study was the detection or exclusion of clinically relevant arrhythmias using ILR during follow-up. Secondly, it was determined whether an ILR finding resulted in a change in patient management defined as an initiation or adjustment of medication, electric or medical cardioversion, electrophysiologic study or ablation, as well as implantation of a cardiac implantable electronic device (CIEDs) such as a pacemaker (PM) or an implantable cardioverterdefibrillator. Moreover, the functional and hemodynamic status of patients with CHD defined by WHO-functional class, peripheral oxygen saturation at rest, and the presence of pulmonary arterial hypertension was correlated with the occurrence and frequency of cardiac arrhythmias.

\section{Statistical analysis}

Continuous data are presented as mean values \pm standard deviation. Categorical variables were summarized using frequency with percentage, respectively. Statistical analysis was performed using Microsoft Excel and SPSS software, version 24.0 (IBM, Armonk, NY, USA).

\section{Results}

\section{ACHD-patient population requiring ILR implantation}

During the study period, an ILR was implanted in a total of 33 patients with CHD, 3 of whom were $<18$ years old (mean age, $43 \pm 20$ years; range $3-78$ years; $42.4 \%$ female). This represents $0.07 \%$ of the 48,000 patients with CHD during the study period of 4 years (about 8,000 annually) at the German Heart Center Munich. The Reveal LINQ (Medtronic, Minneapolis, MN, USA) was used in 24 patients and the Reveal XT (Medtronic, Minneapolis, MN, USA) in 3 patients, respectively. Seven patients received the Reveal Confirm (St. Jude Medical, Sylmar, CA, USA). Baseline characteristics of the study population are presented in Table 1 . The relation of simple, moderate and severe complexity of CHD was balanced. The most common CHD-diagnoses were persistent foramen ovale (PFO), tetralogy of Fallot (TOF), or pulmonary atresia with ventricular septal defect. The average number of surgical procedures was $0.9 \pm 1.2$ per patient. All CHD patients were symptomatic before implantation (100\%).

\section{Arrhythmias in patients with CHD}

Indications for ILR-implantation were a history of prior tachycardia, a high degree of suspicion of atrial fibrillation/ flutter, bradycardia, syncope or palpitations of unclear origin, and cryptogenic stroke or ESUS. All patients had appropriate non invasive arrhythmia monitoring prior to the ILR implantation. A severely impaired systemic ventricular function was not present in any patient $(0 \%)$. A previous non-sustained ventricular tachycardia (VT) was documented in $12.1 \%$ of the study population. Adults with CHD (range, 18-78 years) were also categorized based on their CHD physiologic class as defined in the recent ACHD management guidelines, excluding arrhythmia burden (8). The majority of patients were in ACHD physiologic class B (46.6\%), followed by C (20.0\%). A detailed patient-level description of CHD diagnosis, previous cardiac surgery, and 
Table 1 Baseline characteristics. Baseline characteristics of patients with congenital heart disease in which a loop recorder was implanted $(\mathrm{N}=33)$

\begin{tabular}{|c|c|}
\hline Patient characteristics & Outcome \\
\hline Age (years), median & 44 (range, 3-78) \\
\hline Female sex & $14(42.4 \%)$ \\
\hline Observation period ER (days), median & 708 (range, 100-1,809) \\
\hline $\begin{array}{l}\text { Number of surgical procedures, } \\
\text { mean } \pm \mathrm{SD}\end{array}$ & $0.9 \pm 1.2$ \\
\hline \multicolumn{2}{|l|}{ Indication for implant } \\
\hline Tachycardia & $13(38.2 \%)$ \\
\hline Syncope & $9(26.5 \%)$ \\
\hline Atrial fibrillation & $5(14.7 \%)$ \\
\hline Palpitations & $4(11.8 \%)$ \\
\hline Cryptogenic stroke & $1(2.9 \%)$ \\
\hline Bradycardia & $1(2.9 \%)$ \\
\hline Asymptomatic & $0(0.0 \%)$ \\
\hline \multicolumn{2}{|l|}{ Congenital heart defect } \\
\hline Patent Foramen ovale & $6(18.2 \%)$ \\
\hline $\begin{array}{l}\text { Pulmonary atresia with ventricular } \\
\text { septal defect }\end{array}$ & $3(9.1 \%)$ \\
\hline Tetralogy of Fallot & $3(9.1 \%)$ \\
\hline Brugada syndrome & $3(9.1 \%)$ \\
\hline Atrioventricular septal defect & $2(6.1 \%)$ \\
\hline Ebstein's anomaly & $2(6.1 \%)$ \\
\hline Ventricular septal defect & $2(6.1 \%)$ \\
\hline $\begin{array}{l}\text { Anomalous pulmonary venous } \\
\text { drainage }\end{array}$ & $1(3.0 \%)$ \\
\hline Aortic coarctation & $1(3.0 \%)$ \\
\hline Atrial septal defect & $1(3.0 \%)$ \\
\hline Bicuspid aortic valve & $1(3.0 \%)$ \\
\hline Double outlet right ventricle & $1(3.0 \%)$ \\
\hline Pulmonary valve stenosis & $1(3.0 \%)$ \\
\hline Sinus valsalva aneurysm & $1(3.0 \%)$ \\
\hline $\begin{array}{l}\text { Transposition of great arteries (after } \\
\text { atrial switch) }\end{array}$ & $1(3.0 \%)$ \\
\hline Tricuspid atresia & $1(3.0 \%)$ \\
\hline Fabry disease & $1(3.0 \%)$ \\
\hline Marfan syndrome & $1(3.0 \%)$ \\
\hline Truncus arteriosus communis & $1(3.0 \%)$ \\
\hline
\end{tabular}

Table 1 (continued)

\begin{tabular}{|c|c|}
\hline Patient characteristics & Outcome \\
\hline \multicolumn{2}{|l|}{ Systemic systolic ventricular function } \\
\hline Normal EF (>55\%) & $25(75.7 \%)$ \\
\hline Mild impaired (EF 45-54\%) & $7(21.2 \%)$ \\
\hline Moderate impaired (EF 36-44\%) & $1(3.1 \%)$ \\
\hline Severe impaired (EF $\leq 35 \%)$ & $0(0.0 \%)$ \\
\hline \multicolumn{2}{|l|}{ CHD complexity } \\
\hline Simple & $12(36.4 \%)$ \\
\hline Moderate & $11(33.3 \%)$ \\
\hline Complex & $10(30.3 \%)$ \\
\hline \multicolumn{2}{|l|}{ ACHD physiologic class $(\mathrm{N}=30)$} \\
\hline Class A & $5(16.7 \%)$ \\
\hline Class B & $14(46.6 \%)$ \\
\hline Class C & $6(20.0 \%)$ \\
\hline Class D & $5(16.7 \%)$ \\
\hline \multicolumn{2}{|l|}{ Electrocardiography ( $\mathrm{N}=30)$} \\
\hline Sinus rhythm & $28(93.3 \%)$ \\
\hline$P Q$ interval, if sinus rhythm, ms & $201 \pm 53$ \\
\hline QRS duration, ms & $128 \pm 39$ \\
\hline \multicolumn{2}{|l|}{ Cardiac medication $(\mathrm{N}=30)$} \\
\hline Betablocker & $12(40.0 \%)$ \\
\hline Diuretics & $7(23.3 \%)$ \\
\hline Targeted PAH medication & $6(20.0 \%)$ \\
\hline ACE-inhibitor & $3(10.0 \%)$ \\
\hline ARB & $3(10.0 \%)$ \\
\hline Amiodarone & $2(6.7 \%)$ \\
\hline Digitalis & $2(6.7 \%)$ \\
\hline Calcium channel blocker & $2(6.7 \%)$ \\
\hline Magnesium & $2(6.7 \%)$ \\
\hline
\end{tabular}

Data is presented as $n(\%)$, median and mean \pm SD. ACE, angiotensin converting enzyme; ACHD, adult congenital heart disease; $\mathrm{ARB}$, angiotensin receptor blocker; $\mathrm{CHD}$, congenital heart disease; EF, ejection fraction; ER, event recorder; IQR, interquartile range; ms, milliseconds; SD, standard deviation.

Table 1 (continued) 
Table 2 Overview of patient characteristics and clinical outcome. Patient characteristics and clinical outcome of patients with congenital heart disease presented on a case by case individual level

\begin{tabular}{|c|c|c|c|c|c|c|c|c|c|}
\hline Patient & Gender & Underlying CHD & Surgical status & $\begin{array}{l}\text { Number of } \\
\text { surgical } \\
\text { procedures }\end{array}$ & $\begin{array}{l}\text { Indication for } \\
\text { ILR }\end{array}$ & $\begin{array}{c}\text { Age at ILR F } \\
\text { implantation } \\
\text { (years) }\end{array}$ & $\begin{array}{l}\text { FU with } \\
\text { ILR } \\
\text { (days) }\end{array}$ & $\begin{array}{l}\text { ILR-detected } \\
\text { arrhythmia }\end{array}$ & $\begin{array}{l}\text { ILR-guided } \\
\text { therapy }\end{array}$ \\
\hline 2 & $\mathrm{~F}$ & DORV & $\begin{array}{l}\text { Pulmonary artery } \\
\text { banding }\end{array}$ & 1 & Tachycardia & 55 & 817 & AF, AFL, VT & Ablation, sICD \\
\hline 4 & $\mathrm{~F}$ & Tetralogy of Fallot & Surgical repair & 2 & Syncope & 38 & 749 & - & - \\
\hline 5 & M & $\begin{array}{l}\text { Ebstein's } \\
\text { anomaly }\end{array}$ & Native & 0 & Syncope & 71 & 423 & Recurrent VT & $\begin{array}{c}\text { Modification of } \\
\text { antiarrhythmic } \\
\text { treatment }\end{array}$ \\
\hline 8 & M & Tricuspid atresia & $\begin{array}{l}\text { TCPC, lateral tunnel } \\
\text { technique }\end{array}$ & 2 & Tachycardia & 35 & 1,247 & SVES & $\begin{array}{c}\text { Modification of } \\
\text { antiarrhythmic } \\
\text { treatment }\end{array}$ \\
\hline 9 & M & $\begin{array}{c}\text { Pulmonary atresia } \\
\text { with VSD }\end{array}$ & Modified BTS & 3 & Tachycardia & 20 & 762 & SVT & - \\
\hline 10 & M & $\begin{array}{c}\text { Bicuspid aortic } \\
\text { valve }\end{array}$ & $\begin{array}{l}\text { Replacement of } \\
\text { aortic valve and } \\
\text { ascending aorta, } \\
\text { proximal aortic arch }\end{array}$ & 1 & Tachycardia & 69 & 274 & AT & - \\
\hline 14 & $\mathrm{~F}$ & PFO & $\begin{array}{l}\text { Interventional } \\
\text { closure }\end{array}$ & 0 & Tachycardia & 54 & 184 & SVES, AF, AT & Ablation \\
\hline 15 & M & Ebstein's anomaly & Native & 0 & Detection of AF & 69 & 197 & - & - \\
\hline 16 & $\mathrm{~F}$ & ASD & Native & 0 & Detection of AF & 62 & 702 & VES & - \\
\hline 17 & $\mathrm{~F}$ & $\begin{array}{c}\text { Anomalous } \\
\text { pulmonary venous } \\
\text { drainage }\end{array}$ & Surgical repair & 1 & Syncope & 40 & 1,046 & SVES, VES & - \\
\hline 18 & M & $\begin{array}{l}\text { Sinus valsalva } \\
\text { aneurysm }\end{array}$ & Native & 0 & $\begin{array}{l}\text { Cryptogenic } \\
\text { stroke }\end{array}$ & 33 & 400 & - & - \\
\hline 19 & $\mathrm{~F}$ & Brugada syndrome & Native & 0 & Syncope & 8 & 708 & - & - \\
\hline 20 & $\mathrm{~F}$ & VSD & Native & 0 & Tachycardia & 44 & 713 & nsVT & - \\
\hline
\end{tabular}

Table 2 (continued) 
Table 2 (continued)

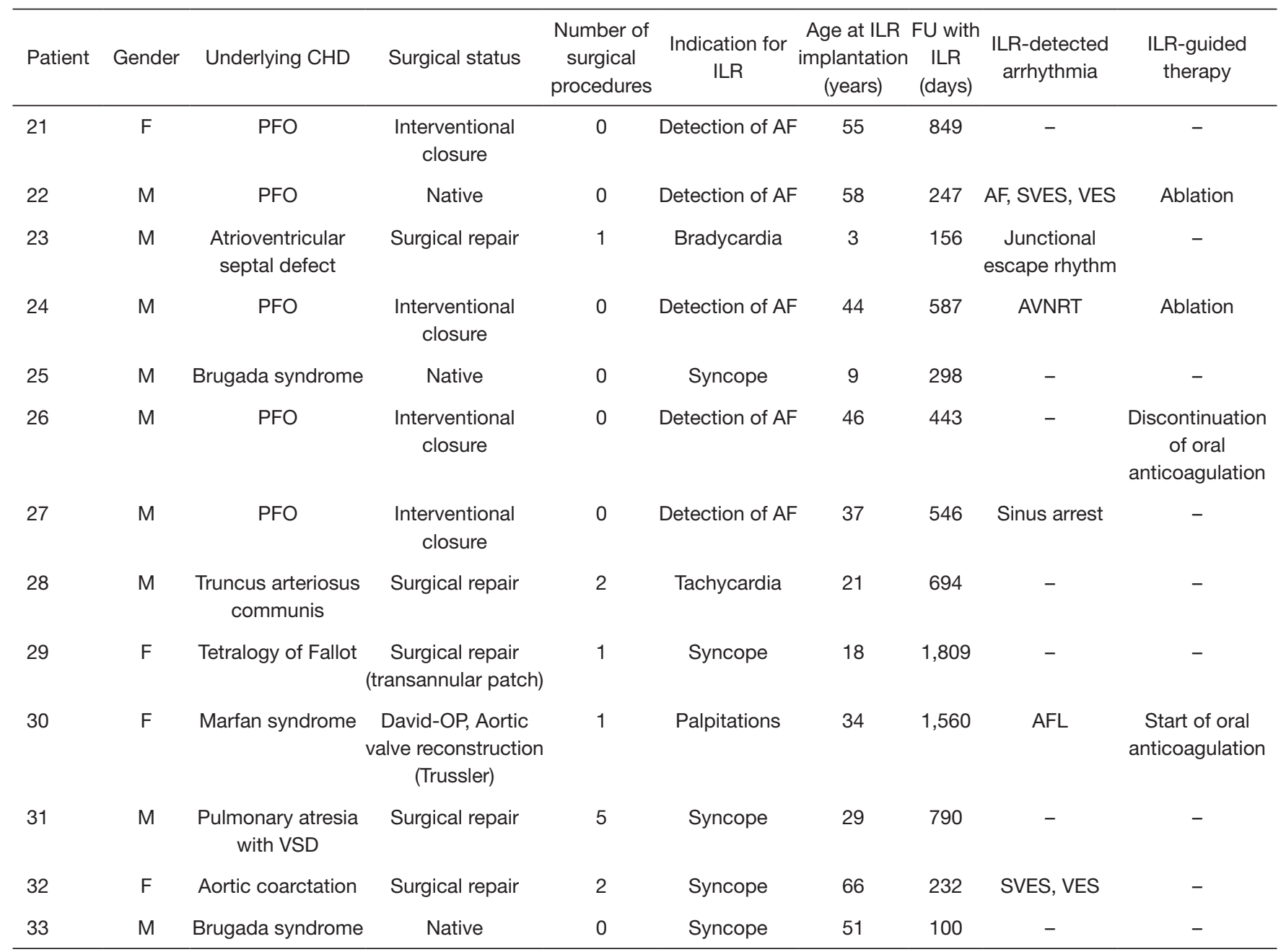

AF, atrial fibrillation; AFL, atrial flutter; ASD, atrial septal defect; AT, atrial tachycardia; AVNRT, AV nodal reentrant tachycardia; DORV, double outlet right ventricle; ICD, implantable cardioverter-defibrillator; ILR, implantable loop recorder; d-TGA, d-transposition of the great arteries; NSVT, non-sustained ventricular tachycardia; PV, pulmonary valve; SVES, supraventricular extrasystole; SVT, supraventricular tachycardia; VES, ventricular extrasystole; VSD, ventricular septal defect; VT, ventricular tachycardia.

reasons for ILR implantation is presented in Table 2.

During a mean observation period of $697 \pm 433$ days, significant arrhythmias were detected in 19 patients (59.4\%), including supraventricular tachycardia $(\mathrm{n}=10)$, VES and/or SVES $(n=10)$, non-sustained ventricular tachycardia $(n=2)$, ventricular tachycardia $(\mathrm{n}=2)$, and bradycardia $(\mathrm{n}=2)$. In 9 patients $(28.1 \%)$ the detected arrhythmia was considered an event requiring treatment and changed the patient management. With regard to this point, there were no significant numeric differences between patients with or without previous surgical procedures due to the underlying congenital heart disease. Figure 1 provides an overview of the type and frequency of the detected arrhythmias.

\section{ILR directed management of patients with CHD}

Management included electrophysiologic study and ablation $(n=5)$, modification of antiarrhythmic drug treatment $(n=2)$, modification of anticoagulation therapy $(\mathrm{n}=2)$, and subcutaneous ICD implantation $(\mathrm{n}=1)$ (Figure 2). Underlying diagnoses among the 9 patients with documented events were: PFO (4/9, 44.4\%), Marfan syndrome $(1 / 9,11.1 \%)$, Fabry disease $(1 / 9,11.1 \%)$, Ebstein'sanomaly $(1 / 9,11.1 \%)$, double outlet right ventricle 


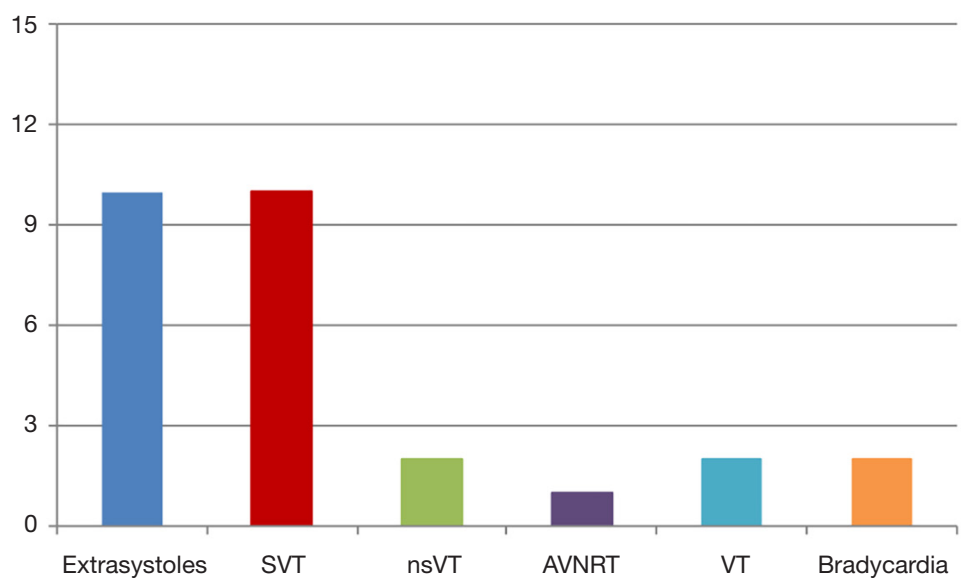

Figure 1 Cardiac arrhythmias detected by Implantable-loop recorder. Type and frequency of detected cardiac arrhythmias. SVT, supraventricular tachycardia; nsVT, non-sustained ventricular tachycardia; AVNRT, AV-node reentry tachycardia; VT, ventricular tachycardia.

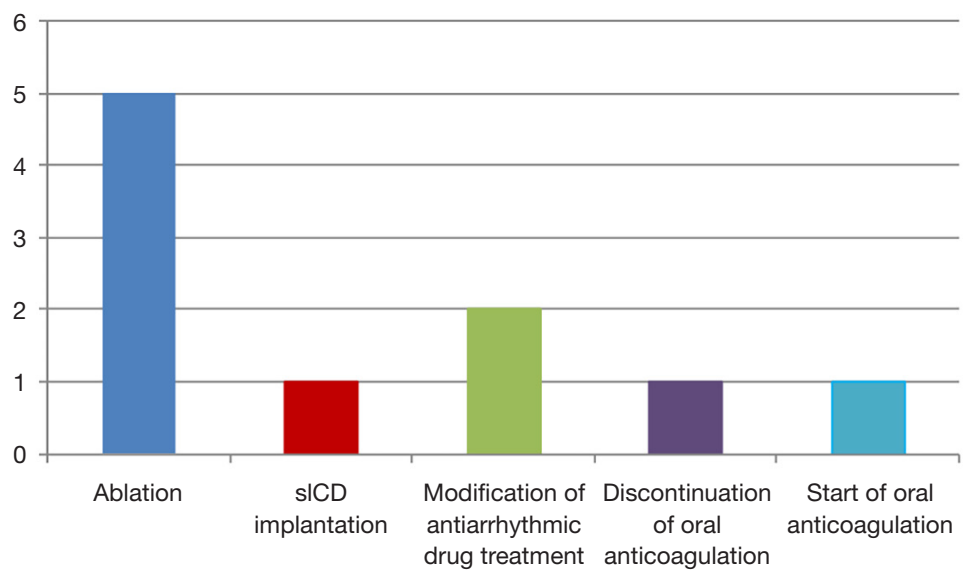

Figure 2 Implantable-loop recorder-guided therapeutic interventions. Display of type and frequency of therapeutic interventions resulting from ILR-detected arrhythmias. sICD, subcutaneous implantable cardioverter-defibrillator.

(DORV) $(1 / 9,11.1 \%)$, and tricuspid atresia (1/9, 11.1\%). In the remaining 24 patients, $50 \%(n=12)$ showed no evidence of threatening cardiac arrhythmias and the results of the ILR did not result in direct therapeutic consequences.

\section{Hemodynamic und functional status of CHD-patients requiring $I L R$}

The majority of patients could be assigned to WHOfunctional class (WHO-FC) I or II (25/33 patients, 75.7\%) and only eight patients were in WHO-FC III (8/33, $24.3 \%)$. No significant differences could be detected between the individual groups regarding the frequency of cardiac arrhythmias or resulting therapeutic consequences. However, cardiac arrhythmias tended to occur more often in den subgroup of patients in WHO-FC II, but without entailing a medical or interventional therapy more frequently.

A total of 8 patients $(24.3 \%)$ had significant pulmonary vascular disease and pulmonary arterial hypertension (PAH) as a particularly susceptible noxious agent. Six out of these received a $\mathrm{PAH}$-targeted drug treatment, including $\mathrm{PDE}$ 5 inhibitors (Sildenafil, Tadalafil), endothelin receptor antagonists (Bosentan, Macitentan), a direct stimulator of 
soluble guanylate cyclase (Riociguat) or inhaled Iloprost. In the subgroup of PAH-patients, arrhythmias were detected in a total of 5 patients by means of ILR, one of which resulted in electrophysiologic ablation therapy. Regarding peripheral saturation $\left(\mathrm{SpO}_{2}\right), 4$ patients were cyanotic with oxygen saturation below $92 \%$ under resting conditions. There were no significant differences between the two groups of patients with normal and cyanotic oxygen saturation regarding the frequency of cardiac arrhythmias ( $7 v s .6$ patients) or resulting therapeutic consequences ( $3 v s .2$ patients).

\section{Safety of ILR-implantation in CHD-patients}

There were no procedure-related complications during ILR implantation. However, the ILR had to be explanted and reimplanted due to wound dehiscence in two patients and was explanted in one patient due to localized pain.

\section{Discussion}

In this single center retrospective observational study, an ILR was implanted in a total of 33 patients during the study period. Significant arrhythmias were detected in 19 out of 33 CHD-patients with help of the ILR device. This led in nine patients $(28.1 \%)$ to a change in clinical management, which included electrophysiologic study and ablation, modification of antiarrhythmic drug treatment, adaption of anticoagulation therapy and subcutaneous ICD implantation. In the other 14 patients $(42.4 \%)$, invasive approaches could be prevented by excluding relevant cardiac arrhythmias.

The identification of high-risk patients and risk stratification are so far unsolved problems in the followup of patients with CHD although prevention of sudden cardiac death is essential in this group, especially in ACHD. As the study data show, the use of an ILR as a simple and safe implantable device is becoming increasingly valuable to detect or exclude threatening cardiac arrhythmias in patients with CHD at risk (8).

Arrhythmias are a leading cause of mortality and morbidity in the CHD population, often resulting from myocardial fibrosis, postoperative scars or deterioration of the hemodynamic situation, such as pathological pressure and volume loads or chronic hemodynamic stress and remodeling processes (3). Particularly affected are patients with native or surgically repaired atrial septal defect, tetralogy of Fallot, transposition of the great arteries after atrial redirection, univentricular hearts after Fontan operation or with Ebstein's anomaly (6). Monomorphic and polymorphic ventricular tachycardias as well as ventricular fibrillation are the most important ventricular tachyarrhythmias, preferably occurring as a late complication after ventriculotomy, after patch closure of ventricular septal defects, after Fallot repair or after Rastelli-type operation for transposition of the great arteries (11). Supraventricular arrhythmias, such as intraatrial re-entry tachycardias and atrial flutter, are even more prevalent and account for approximately $75 \%$ of all cases of cardiac arrhythmias in patients with CHD. They result from surgical incisions and scarring, which may promote the development of macro re-entry tachycardias. Such atrial tachycardias are important risk factors for sudden cardiac death in CHD patients with impaired ventricular function, occurring with a risk of $2 \%$ to $9 \%$ per decade (4).

As a consequence of the high incidence of malignant arrhythmias, causing palpitations, syncope, heart failure or even cardiac death, there is a deep need for accurate detection and monitoring of CHD patients as well as for the timely initiation of preventive or therapeutic measures.

To date, there is only limited data regarding the diagnostic value of an ILR in children and adults with CHD. Sakhi et al. reported a high incidence of ILR-detected heart rhythm disturbances in adults with CHD who were deemed at risk for these cardiac arrhythmias. Subsequently, ILR results led to implantation of an ICD in $10 \%$ of their CHD population (9). In another study, clinically relevant events were detected by ILR in $41 \%$ of patients. In their study, especially patients after Fontan operation and ACHD physiology of class D had the highest prevalence of events leading to changes in clinical management (10). Bezzerides et al. reported on 34 patients, mostly children and only a few adults with CHD, aging between 3.6 months to 44.6 years at implantation. Syncope was the most common indication, and the average time to diagnosis was less than 5 months and the ILR provided useful data in more than half of the patients (12).

In our cohort, during the observation period the use of ILR detected clinically relevant arrhythmias in about a quarter of included CHD patients (9/33, 28\%), leading to direct therapeutic consequences or an adjustment of the clinical management. This included one patient with DORV and the implantation of an ICD for ventricular tachycardia. In eight other cases either electrophysiologic studies and catheter ablation or an adjustment of the medical therapy was required. In the remaining patients $(24 / 33,72 \%)$, either no malignant cardiac arrhythmia could be detected at all, 
or the clear identification of the type of arrhythmias and definite exclusion of malignant arrhythmias precluded the need of further therapeutic measures.

Compared to previous data in literature, in our cohort only in a minority of patients events were detected requiring a change in medical treatment or ICD implantation. These differences may be explained in part by the heterogenous group of our patients with predominantly simple to moderate CHD complexity.

Furthermore, it is important to note that in our study the suspicion of malignant arrhythmias in symptomatic patients could be widely excluded. This is so important as ICD therapy comes particularly in patients with CHD along with a considerable somatic and psychological burden from appropriate or inappropriate shocks, as well as device or lead malfunction (13-15). The exclusion of malignant arrhythmias may have prevented patients from receiving an ICD or PM without a compelling indication as a preventive measure.

Furthermore, our data provide a low complication rate in this subgroup of adult patients with CHD, as there were no procedure-related severe complications from ILR implantation. During follow-up, nevertheless, the ILR had to be revised and re-implanted because two patients experienced wound dehiscence and one patient required definitive explantation due to subjective severe localized pain.

In our study, the ILR had a high supplementary diagnostic value for the evidence or the exclusion of malignant arrhythmias in 33 symptomatic CHD-patients with a risk profile for clinically relevant arrhythmiaassociated palpitations, syncope or cardiac death. Due to the advantages and the low complication rate an ILR can be considered in symptomatic CHD-patients of all complexities, especially if other modalities are not able to provide adequate diagnostic safety.

\section{Study limitations}

One of the limitations is the retrospective nature and the single-center design of this study. Moreover, the study is underpowered to identify potentially clinically relevant findings as statistically significant. The study includes a so far relatively small and heterogeneous cohort of patients with CHD of all complexities. The relatively small number of patients with severe CHD and the resulting overall small number of surgical procedures due to the underlying congenital heart disease may have affected the low number of relevant cardiac arrhythmias in CHD-patients in general. However, since the occurrence of palpitations and unclear cardiac symptoms is a common phenomenon in adults with any type of CHD, our study provides important insights into the diagnostic benefit of an ILR implantation in patients with CHD.

\section{Conclusions}

In symptomatic CHD-patients with a certain risk of cardiac or neurologic complications, the ILR has a high supplementary diagnostic value for the exclusion of malignant arrhythmias with an overall acceptable risk. In the remaining cases where no malignant cardiac arrhythmia can be detected further therapeutic measures that burden or endanger the patient can be avoided. Therefore, ILRimplantation in patients with CHD of any complexity should be considered, especially if long-term ECGs cannot provide sufficient diagnostic safety.

\section{Acknowledgments}

The authors would like to thank the patient organization "Herzkind e.V.", the German Heart Foundation ("Deutsche Herzstiftung e.V."), and also the German health care insurance AOK-Bayern for the promotion of ACHD research. We further thank Dr. Nikolaus Schumacher, Nambaya GmbH, Gruenwald, Germany, for his support of research and medical care for patients with congenital heart disease. Finally, we thank Iris Thuerbach (Psychosocial ACHD-Service, ACHD-Center Cologne, Heart Center Cologne, Germany) for her support in data acquisition.

Funding: None.

\section{Footnote}

Provenance and Peer Review: This article was commissioned by the editorial office, Cardiovascular Diagnosis and Therapy for the series "Current Management Aspects in Adult Congenital Heart Disease (ACHD): Part IV". The article has undergone external peer review.

Reporting Checklist: The authors have completed the STROBE reporting checklist. Available at http://dx.doi. org/10.21037/cdt-20-677

Data Sharing Statement: Available at http://dx.doi. org/10.21037/cdt-20-677

Conflicts of Interest: All authors have completed the 
ICMJE uniform disclosure form (available at http:// dx.doi.org/10.21037/cdt-20-677). The series "Current Management Aspects in Adult Congenital Heart Disease (ACHD): Part IV" was commissioned by the editorial office without any funding or sponsorship. HK serves as an unpaid editorial board member of Cardiovascular Diagnosis and Therapy from February 2018 to January 2022. and served as the unpaid Guest Editor of the series. CK reports non-financial support from Abbott Medical, personal fees and non-financial support from Biotronik, personal fees from Bristol-Myers-Squibb, personal fees from Microport, personal fees from Novartis, personal fees from Philips, other from Abbott Medical, from Biotronik, other from Boston Scientific, other from Microport, outside the submitted work. The authors have no other conflicts of interest to declare.

Ethical Statement: The authors are accountable for all aspects of the work in ensuring that questions related to the accuracy or integrity of any part of the work are appropiately investigated and resolved. The study was conducted in accordance with the Declaration of Helsinki (as revised in 2013). The study was reviewed and approved by the local Ethics Committee of the medical faculty at the University of Cologne (vote 20-1526) and individual consent for this retrospective analysis was waived.

Open Access Statement: This is an Open Access article distributed in accordance with the Creative Commons Attribution-NonCommercial-NoDerivs 4.0 International License (CC BY-NC-ND 4.0), which permits the noncommercial replication and distribution of the article with the strict proviso that no changes or edits are made and the original work is properly cited (including links to both the formal publication through the relevant DOI and the license). See: https://creativecommons.org/licenses/by-nc-nd/4.0/.

\section{References}

1. Hoffman JI. The global burden of congenital heart disease. Cardiovasc J Afr 2013;24:141-5.

2. Neidenbach R, Kaemmerer H, Pieper L, et al. Striking Supply Gap in Adults with Congenital Heart Disease? Dtsch Med Wochenschr 2017;142:301-3.

3. Nieminen HP, Jokinen EV, Sairanen HI. Causes of late deaths after pediatric cardiac surgery: a population-based study. J Am Coll Cardiol 2007;50:1263-71.

4. Oechslin EN, Harrison DA, Connelly MS, et al. Mode of death in adults with congenital heart disease. Am J Cardiol 2000;86:1111-6.

5. Opotowsky AR, Siddiqi OK, Webb GD. Trends in hospitalizations for adults with congenital heart disease in the U.S. J Am Coll Cardiol 2009;54:460-7.

6. Moe TG, Abrich VA, Rhee EK. Atrial Fibrillation in Patients with Congenital Heart Disease. J Atr Fibrillation 2017;10:1612.

7. Perloff J, Child J, Aboulhson J. Congenital heart disease in adults. Philadelphia: WB Saunders; 2008.

8. Stout KK, Daniels CJ, Aboulhosn JA, et al. 2018 AHA/ ACC Guideline for the Management of Adults With Congenital Heart Disease: A Report of the American College of Cardiology/American Heart Association Task Force on Clinical Practice Guidelines. Circulation 2019;139:e698-e800.

9. Sakhi R, Kauling RM, Theuns DA, et al. Early detection of ventricular arrhythmias in adults with congenital heart disease using an insertable cardiac monitor (EDVA-CHD study). Int J Cardiol 2020;305:63-9.

10. Dodeja AK, Thomas C, Daniels CJ, et al. Detection of arrhythmias in adult congenital heart disease patients with LINQTM implantable loop recorder. Congenit Heart Dis 2019;14:745-51.

11. Nieminen HP, Jokinen EV, Sairanen HI. Causes of late deaths after pediatric cardiac surgery: a population-based study. J Am Coll Cardiol 2007;50:1263-71.

12. Bezzerides VJ, Walsh A, Martuscello M, et al. The RealWorld Utility of the LINQ Implantable Loop Recorder in Pediatric and Adult Congenital Heart Patients. JACC Clin Electrophysiol 2019;5:245-51.

13. Yap SC, Roos-Hesselink JW, Hoendermis ES, et al. Outcome of implantable cardioverter defibrillators in adults with congenital heart disease: a multi-centre study. Eur Heart J 2007;28:1854-61.

14. Vehmeijer JT, Brouwer TF, Limpens J, et al. Implantable cardioverter-defibrillators in adults with congenital heart disease: a systematic review and meta-analysis. Eur Heart J 2016;37:1439-48.

15. Opic P, Utens EM, Moons P, et al. Psychosocial impact of implantable cardioverter defibrillators (ICD) in young adults with tetralogy of Fallot. Clin Res Cardiol 2012;101:509-19.

Cite this article as: Huntgeburth $\mathrm{M}$, Hohmann C, Ewert P, Freilinger S, Nagdyman N, Neidenbach R, Pieper L, Pieringer F, Lennerz C, Kaemmerer H, Kolb C. Implantable loop recorder for monitoring patients with congenital heart disease. Cardiovasc Diagn Ther 2021;11(6):1334-1343. doi: 10.21037/cdt-20-677 